\title{
Enterprise-wide analytical solutions for distribution planning
}

Received (in revised form): 24th July, 2003

\section{Keith Peterson}

is President of Integras, a division of Claritas Inc. Integras provides market analysis systems for large retailers and financial services companies in the USA. For the past 12 years, he has helped companies optimise their capital investments, operations and store network performance using analytical software and consulting. Mr. Peterson has a doctorate in psychology from Vanderbilt University.

Abstract Today's retail business leaders use enterprise-wide decision support tools to guide market expansion strategy and optimisation of existing networks. In particular, distribution planning models are deployed to guide site selection, determine store formats and optimise store networks. These models, however, require the integration of an array of transaction, customer and demographic market data. Once combined, special methods are required to meet the unique assumptions of geospatial analysis and to handle data collected at different levels of aggregation. This paper reviews the use of analytical models within distribution planning systems. A typical distribution planning system is described. Technology, data and analytical components are detailed. Then five key applications are described for retail and banking.

\section{CUSTOMERCENTRIC DISTRIBUTION PLANNING}

For retail businesses, few decisions are as expensive and permanent as where to place new stores. Progressive retailers use distribution planning systems to minimise risk in these capital investments and to identify significant opportunities for growth. By integrating customer, market and channel information in these systems, companies can prioritise markets for development, optimise channels to deliver their products and evaluate store network performance against market potential. While the use of market data in distribution planning is not new, there have been significant advances in recent

Keith Peterson Integras, 5375 Mira Sorrento Place, Suite 400, San Diego, CA 92130, USA.

Tel: +1 800866 6520; e-mail: kpeterson@ integrasconsulting.com; website: www.integrasconsulting.com years in the sophistication of data warehouses and in analytical tools. These tools allow for analytics that reach farther across the enterprise and inform a range of high-level strategic decisions as well as day-to-day tactical decision making.

The author's firm's consultants have helped numerous organisations design, develop and implement enterprise-wide distribution strategies. Techniques for customer targeting that utilise database marketing strategies can significantly improve distribution planning.

Furthermore, market-level analyses from distribution planning systems provide valuable information to marketing departments, as companies seek to optimise strategies across retail, direct and online channels.

This paper presents a prototypical enterprise-wide distribution planning system useful for multichannel distribution planning. It then describes a set of analytical applications that represent best practices in the field.

\section{COMPONENTS OF A DISTRIBUTION PLANNING SYSTEM}

Distribution planning systems integrate internal and external data with spatial 


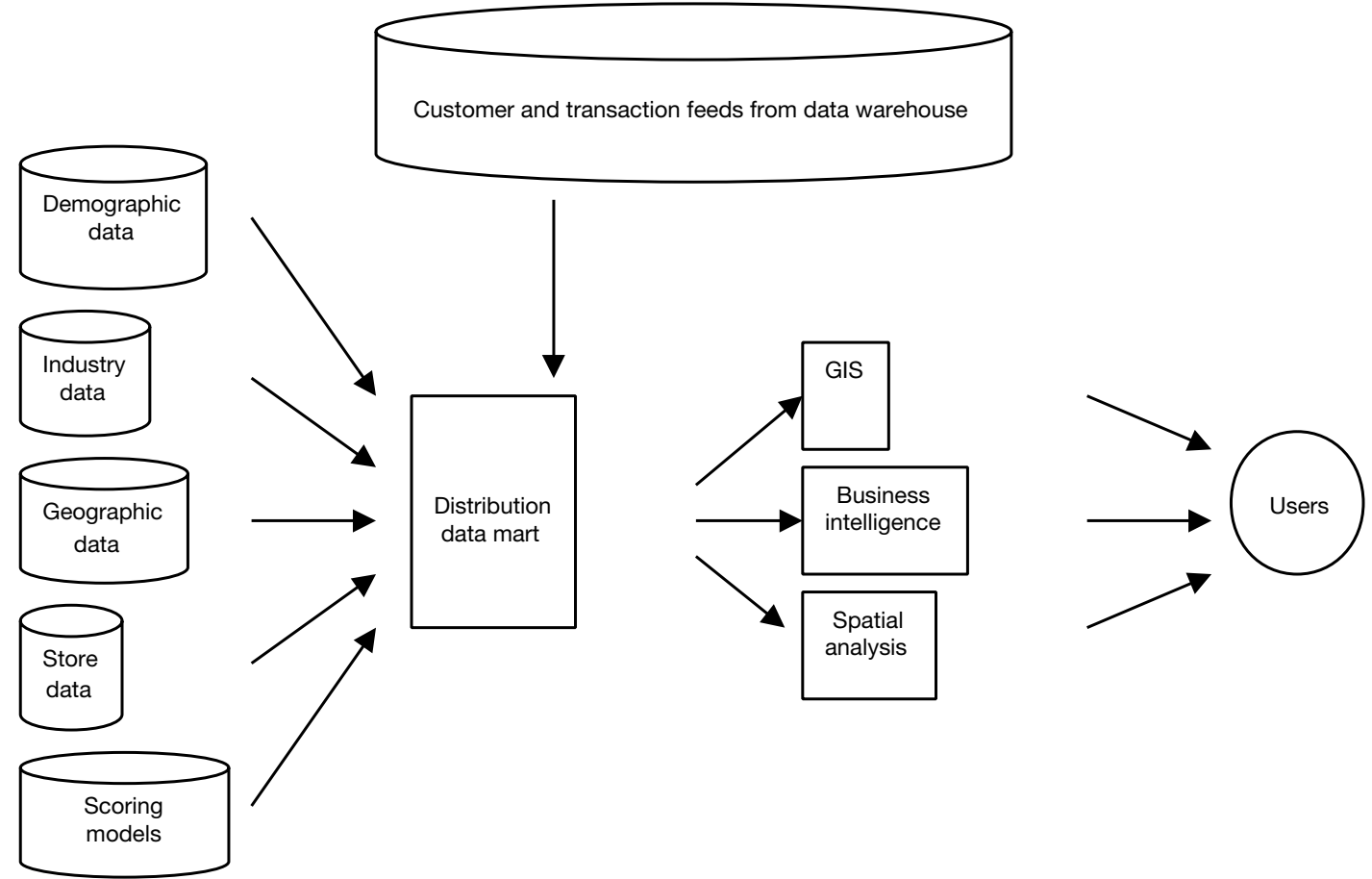

Figure 1: Distribution planning system design

and quantitative analysis tools and geographic information systems technology to support the major functions of market scanning and local area analysis, market segmentation and customer profiling and performance analysis and site location. These systems are typically implemented as data marts (small specialised databases and applications attached to a large corporate data warehouse), linking into financial, operational and external data sources. Figure 1 presents a schematic of such a system. The main components of the systems include hardware, software, network connectivity and data.

Successful enterprise-wide distribution planning systems must manage large volumes of data and analyse those data in ways that can be distributed to diverse audiences at the executive, management and technical/field levels. A significant challenge arises in the integration of diverse internal and external commercial data. Data structures may differ across sources, making it difficult to resolve discrepancies by data source.

Large-scale distribution planning systems cannot succeed without support from technology experts. Distribution planning groups often find, however, that the management information system (MIS) department presents a barrier to implementation. These barriers usually stem from some basic misconceptions.

First, companies often believe MIS departments have the knowledge and tools to build accurate distribution planning tools. In reality, MIS is typically involved in operational systems and not specialised analytical tools. For example, the regimented uses of data by accounting divisions, for example, does not mirror the way real estate analysts use data for market prioritisation studies, market share analysis and network optimisation. Most knowledge and tools that MIS use in building operational data systems do not apply to distribution planning. 
Secondly, MIS departments often believe that when building a system, distribution planning groups cannot communicate what they want. However, market analysis requirements again differ significantly from other business requirements. Market planners cannot communicate a complete and fixed set of requirements because their most important requirement is the ability to handle constantly-changing reporting and analysis needs.

Thirdly, companies often initially believe that relational queries provide sufficient flexibility for accessing and analysing data. When handling individual customer and geographic-level data, there is far greater need for complex data transactions and statistical aggregation in an efficient manner. Because of this need, marketing analysts use specialised tools, including geographic information systems software and customised spatial analysis software.

\section{Technology infrastructure}

Distribution planning systems are typically 'big' because they require integration of a broad array of data, advanced forms of statistical and spatial modelling, and the distribution of results to users with diverse needs. The author's experience is that effective distribution planning systems operate flexibly as a system of integrated databases and tools compiled from a range of suppliers. The architecture for these systems is dictated by need, cost, flexibility, ease-of-use, and specialisation of analytical applications.

Usually deployed as data marts linked to a corporate data warehouse, these systems encompass database technology, geographic information systems (GIS), business intelligence tools, spatial analysis tools for modelling, scenario planning and report generation (Table 1 presents a sample of commercially available applications). Geographic market analysis requirements also necessitate tools for data cleansing and consolidation, aggregation of individual customer and store data to different levels of analysis, and the ability to link customer, transaction, product and channel data from various data sources using persistent keys.

Modern distribution planning systems rely on database technology that is customer and geographic-centric. This has implications for the performance of databases that support the system. Most importantly, the systems must aggregate and disaggregate a combination of individual customer data and summarise geographic data flexibly and quickly to support a range of analytical purposes. These unique functions require a system that is able to:

- access and consolidate large volumes of data including customer data, market data and geographic data

- incorporate additional commercial data on an ad hoc basis

- process customer and market data to identify core market segments and project these segments into small geographic areas for evaluation purposes

- modify files and fields to store and share information like trade area definitions, market share calculations and demographic updates to changing boundary definitions

- support for scenario analysis and 'what-if' modelling including interactive response times for a range of queries, modelling and reporting.

Depending on need, companies deploy systems as desktop, client-server and web applications. Desktop systems are ideal for less data-intensive applications. Data can be pre-summarised and loaded in the system in standard file formats. Queries 
Table 1: A sample of tools for distribution planning systems

\begin{tabular}{lll}
\hline Company & Product & Type \\
\hline Claritas, Inc. & IMARK & Demographic data \\
& IMARK Online & Retrieval \\
& IExpress & \\
Cognos, Inc. & Precision Code & Geocoding \\
ESRI, Inc. & Impromptu/PowerPlay & Business intelligence \\
GDT, Inc. & ArcView & GIS \\
Geo Vue & Dynamap 2000 & Geocoding \\
& Isite & Demographic data \\
Integras & Nexus & retrieval \\
Maplnfo & Maplnfo & Market modelling \\
Microsoft & MapPoint & GIS \\
Corp. & Microsoft SQL & GIS \\
Micostrategy & Database \\
Oracle & Oracle Spatial & Business intelligence \\
& Oracle 9ai & Spatial query \\
SRC & Allocate & Database \\
Tactician & Tactician & Demographic data retrieval \\
\hline
\end{tabular}

and analyses can be run using GIS; and users can customise programming scripts to run production models for sales forecasting, impact analysis and market optimisation.

Client-server implementations are most common and provide the ability to link customer data warehouse extracts, files of commercial data and store or branch-level performance data. Data processing can be done on centralised servers and passed to GIS and spatial analysis tools for interactive analysis. In most cases where large market areas or many data points are analysed, a client-server environment is most attractive for performance reasons.

Web-enabled implementations are increasingly popular. These systems allow deployment to remote users through browser-based applications. Support costs are lower and more field personnel are able to leverage system output. Web-based systems are less practical, however, for users who generate detailed maps and reports that cannot be passed easily over the internet or an intranet because of large file sizes. Additionally, many companies have data security policies that limit the transfer of customer or other sensitive data outside network firewalls.

\section{Data}

Distribution planning systems revolve around a core set of data and key metrics: geographic boundaries, measures of market opportunity within those boundaries, competitive challenge and market share potential, and barriers and facilitators to growth. Using these data, market analysts can address such questions as:

- how should we prioritise national markets for expansion

- is our store or branch network optimised within our market footprint

- what happens to overall network performance when we add/move/ refurbish/close a location

- what is the most profitable mix of company stores and mass channel business?

Table 2 shows a typical data catalogue including the categories of interest and operationalisations of a set of data variables typical to banking. These core 
Table 2: Sample bank data catalogue

\begin{tabular}{|c|c|c|}
\hline Customers & $\begin{array}{l}\text { Retail consumer } \\
\text { Small business } \\
\text { Corporate cccounts }\end{array}$ & Internal - data warehouse \\
\hline Products & $\begin{array}{l}\text { Deposits }- \text { balances } \\
\text { Investments } \\
\text { Loans }\end{array}$ & Internal \\
\hline Channel & $\begin{array}{l}\text { Branch } \\
\text { ATM } \\
\text { Call centre } \\
\text { Website } \\
\text { Point-of-sale } \\
\text { Non-traditional venue (grocery) }\end{array}$ & Internal \\
\hline Demographic & $\begin{array}{l}\text { Market segments } \\
\text { Consumer } \\
\text { Business }\end{array}$ & Commercial \\
\hline Competitors & $\begin{array}{l}\text { Locations } \\
\text { Market share Top } 5 \\
\text { Relative market share (Market share/ } \\
\text { Market share next closest competitor) }\end{array}$ & Commercial \\
\hline Market-level product usage & $\begin{array}{l}\text { Deposits } \\
\text { Credit } \\
\text { Investments } \\
\text { Loans }\end{array}$ & Commercial \\
\hline Site and area data & $\begin{array}{l}\text { Business locations } \\
\text { Employment } \\
\text { Traffic counts }\end{array}$ & Commercial \\
\hline Geographies & $\begin{array}{l}\text { Census (block group, census tract, } \\
\text { county, MSA, state, region) } \\
\text { Postal (ZIP }+4 \text {, ZIP) } \\
\text { Custom (trade area polygons) }\end{array}$ & Commercial \\
\hline
\end{tabular}

data sets are an integration of internal and external data sources. Internal data include customer and transaction data by channel. External data include market information as a base or benchmark against which to compare and contrast internal customer information for market share, demand potential and growth potential measurement.

While demographic and store location data are geographic-centric, many non-geographic data such as transactional patterns, staffing and store format are also critical to a holistic view of a distribution network. GIS and spatial analysis tools provide the ability to link all these data together through geographic units. For example, a store's actual sales in a market can be predicted as a function not only of demographics and market features but also by operational quality. This type of analysis is useful for diagnosing performance problems and identifying best practices that can be leveraged across a network.

Distribution planners are now leveraging the vast volume of data generated from point-of-sale systems. While marketers link scanner and transaction data to individual households for target marketing analytics, these data can also aggregate to a store/branch level, sales area or regional level for network planning. The key problem is to extract relevant information quickly and easily from the massive operational databases and feed them into a GIS. To date, the most efficient enterprise distribution planning systems draw extracts from these data sources in a pre-summarised manner and then load them into GIS or business intelligence tools for analysis and reporting. 
$100 / 1000$

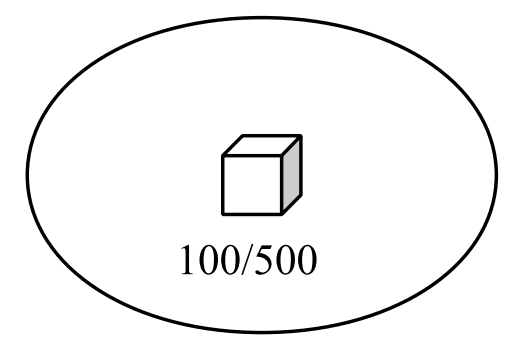

Wealth segment $=20 \%$ Composition

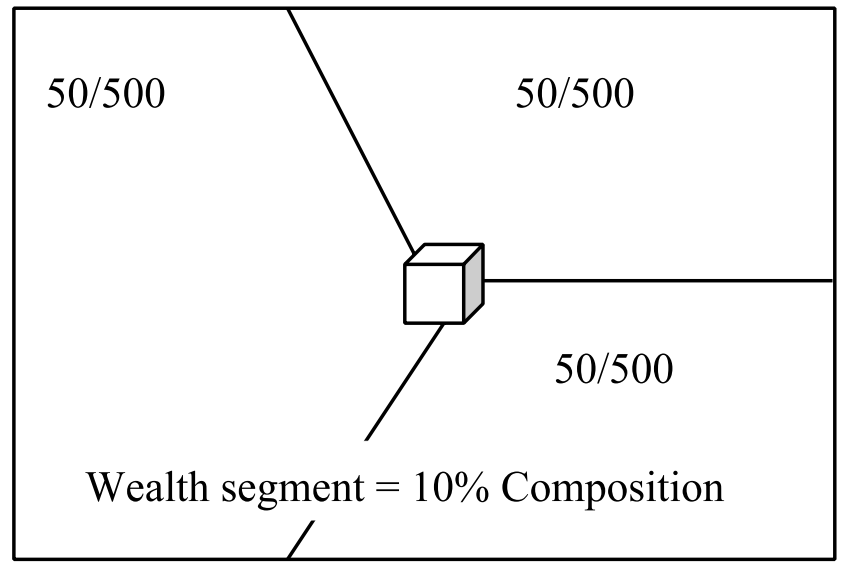

Figure 2: Impact of data aggregation on ecological validity

\section{Geography and analytical validity}

Handling of geographic data for market analysis purposes makes distribution planning systems complex.

Methodological issues arise with respect to integrating diverse data sets and different data structures. First, it is necessary to match attributes or locational characteristics of households with geographic aggregations such as block groups, census tracts or custom sales territories. It is not always possible, however, to ascribe geographic attributes to individuals or point locations

accurately. This problem, the 'ecological fallacy' is difficult to solve and makes it much more critical to rely on judgment and the art of distribution analysis than on pure modelling.
Secondly, geographic units may assume different characteristics at different levels of aggregation. For example, the immediate neighbourhood around a suburban bank branch, defined by a one-mile radius, may show a 20 per cent concentration of wealth segment customers. When, however, the market is measured as an aggregation of two or more geographic units in the same area, and those units encompass both wealth segment neighbourhoods and middle-income neighbourhoods, the concentration of target wealth consumers may appear diluted simply as a function of the geography data collection units. As such, making inferences from aggregations of geography to individual 
locations poses threats to the validity of any spatial analysis.

Because it is not always possible to solve these data complexities, it becomes critical for the enterprise to share a common set of business rules about how to handle them. To do so, successful implementations typically establish a common language for:

- geographic aggregations (common geographies used across functional areas and aggregation rules standardised)

- market segment definitions (in particular, the use of census-based geodemographic segmentation systems allow for a standardised data ascription to geography).

A third source of potential error in integrating data from data sources is mismatching of these data as they are layered onto each other for analysis. For example, the author's firm worked to integrate three business location data sets to compile a complete business census for a bank client. Each data set provided geographic coordinates for each location. The software used to derive the coordinates (called geocoding) varied by data set however. The result was a high proportion of positional inconsistencies across files. The solution for such a situation is to geocode all data sets with the same software. Again, because every geocoder has its own strengths and limitations, it is important to set corporate software standards for geocoding.

\section{BOUNDARY DELINEATION}

Distribution planners use a combination of standard and custom geographies to create network boundaries. Standard census geographies (including block groups, census tracts and counties) provide a consistent and convenient way to disaggregate the market for small area analysis. Business potential is projected into individual geographic units and distribution points are placed to maximise market coverage and minimise capital investment.

Trade areas delineate the unique market area served by a single distribution point. Retailers may use transasctional data or customer surveys to determine the extent and shape of store trade areas. A rule-of-thumb is to identify the geographic areas that encompass 50 per cent or more of customers. Retail banks face a more difficult challenge because customers frequently bank at locations other than where they opened their accounts. For trade area analysis, most banks set more specific business rules such as assigning customers to the branch where they bank most frequently and most recently.

Once built, trade areas form the basis for market analyses and become a key tool to linking disparate customer, market and channel data. Trade areas may be aggregations of block groups or other small geographies like census tracts or postcodes around stores. Trade areas are typically updated at least annually as store networks and market conditions change. Once developed, trade areas can then be aggregated into hierarchies for geographic and operational analysis.

An important consideration in determining how a system will aggregate trade areas for analysis is whether to allow the trade areas to be overlapping over non-overlapping. Overlapping trade areas represent the collective coverage of stores in a market and are critical for understanding sales transfers and customer flows in the market (see Figure 3). When aggregating market potential numbers up from trade area estimates, however, summing across overlapping trade areas overestimates the true market 


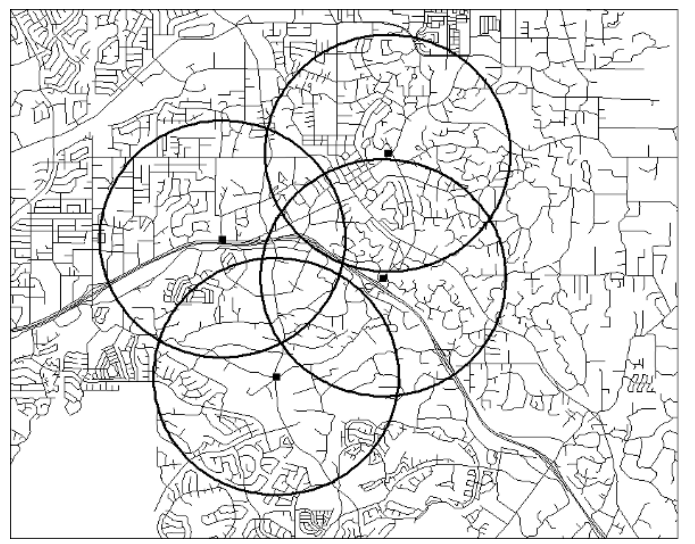

Figure 3: Overlapping and non-overlapping trade areas

potential. In these cases, companies use non-overlapping trade areas that allocate potential between trade areas before summation.

Custom geographies are often composed of aggregations of store trade areas. These geographies provide more a refined view of the local market and allow for the assessment of market efficiency by assessing the extent of store overlap across trade areas. These types of analyses are important, for example, in determining whether a new location will capture new customers or merely steal them from a nearby sister location (called cannibalisation or sales transfer).

\section{FIVE KEY USES OF A DISTRIBUTION PLANNING SYSTEM}

\section{Trade area analysis and network planning}

Trade areas are the basic building blocks in distribution planning. By integrating all internal and external data at the lowest level of geography, planners can study market features and customer characteristics at the store level and then summarise them at the market level. This integration provides a lens to view market conditions at different levels of resolution; and, it eliminates many

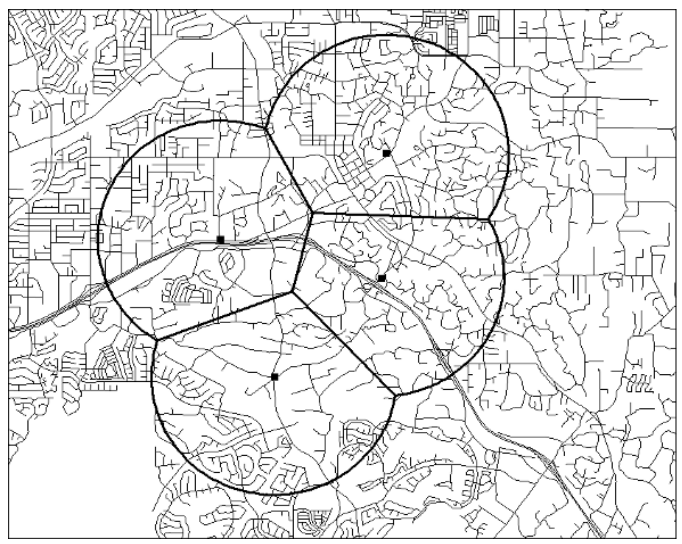

inconsistencies resulting from pulling data from different data sources at different levels of aggregation.

The distribution planning department uses trade areas to assess network efficiency. A store trade area profile provides a quick view of the network distribution points or the network overall. By creating an average store trade area profile, the retailer establishes a basis of comparison for other locations.

By overlaying all trade areas on individual locations, the degree of overlap and potential redundancy can be assessed. Some overlap may be desirable to ensure customer convenience, establish a defensible competitive position, or simply to tie up good real estate. Network planners, however, generally seek to minimise overlap; otherwise, stores will cannibalise sales. The optimal level of overlap depends on the market type.

Downtown and urban areas require denser networks to serve daytime foot traffic and balance peak traffic periods during lunch and before and after work. Suburban areas may be better served by strategically placed locations that intercept traffic in commuter patterns with larger store formats.

Sizing up market opportunity is accomplished by examining the ease of 
Table 3: Sample market weighting factors

\begin{tabular}{lc} 
Market size & $30 \%$ \\
Current and five-year household estimates & $20 \%$ \\
Business and employment density & $10 \%$ \\
& \\
Market attractiveness & $40 \%$ \\
Current and five-year deposit potential & $20 \%$ \\
Presence of wealth segments & $20 \%$ \\
Competitive set & $15 \%$ \\
Households per branch & $5 \%$ \\
Market share of top competitors & $5 \%$ \\
Deposits per branch & $5 \%$ \\
Current retail presence & $15 \%$ \\
Share of households & $5 \%$ \\
Deposits & $5 \%$ \\
Average revenue per household & $5 \%$ \\
\hline
\end{tabular}

market entry and market share potential. Market entry is driven by untapped demand potential in the area. It is driven primarily by household mass and presence of target market segments for product. Market share potential is a function of the store network density, relative to competitors, and other factors like media spend.

\section{Market prioritisation and selection}

Physical distribution analysis must support key business decisions around market expansion. Market prioritisation helps determine what geographic markets are best candidates for a new concept or expansion for an established retailer.

The key audience for market prioritisation studies is primarily toplevel executives and corporate boards. Decisions about which markets to invest in and how much resource to allocate in those markets are highly consequential. For large companies, the decisions have long-term implications and may dictate the allocation of hundreds of millions of dollars. For new concepts, once a market strategy is selected there will be few opportunities to change direction without significant additional investment.

Market prioritisation studies are led by the senior real estate or marketing manager and executed by a team of senior statisticians and market analysts. The team seeks to identify the most attractive markets based on mass, growth potential, existing presence and media efficiencies.

A typical market prioritisation study proceeds in a set of stages. First, for each market area, a set of key metrics are selected and used to create a composite score for evaluation (see Table 3). These metrics are compiled from a combination of data sources to assess demand potential and market share, barriers to entry, strength of existing retail presence and media reach efficiencies.

Although these metrics may be compiled from the aggregation of custom trade area data, it is often the case that the data processing burden is high and the linking of various data sets to custom geographies is cumbersome. Many retailers find that aggregating the data to standard county-level geographies is more efficient and provides comparable results for large market comparisons.

Once markets are ranked and sorted on the composite score, they can be profiled on a range of factors such as household density, competition and growth potential (see Figure 4). These 


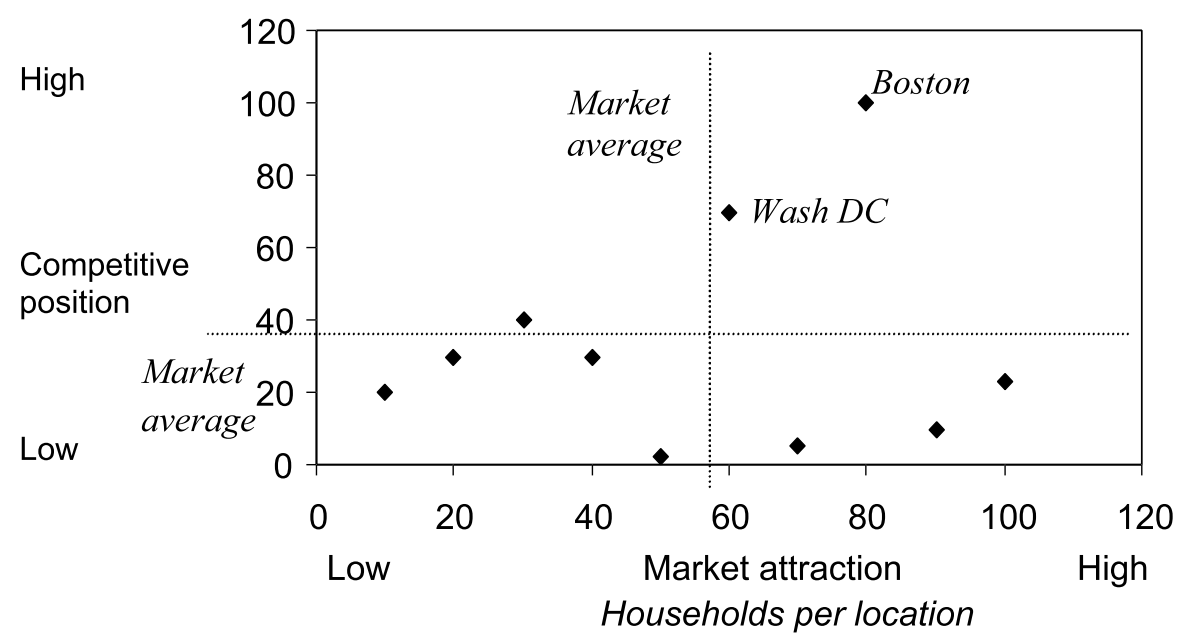

Figure 4: Market scoring

diagnostic analyses are critical to a relative comparison of markets (see Table 4). These profiles also help build consensus because they allow each decision maker to see the variables most important to them.

\section{Store typing}

For performance analysis, treating all stores in a network the same is too simplistic. For example, restaurants operating in downtown locations may draw primarily from dense foot traffic during commutes and lunch periods while suburban locations may draw from local residential neighbourhoods during dinner and weekend periods. As a result, these restaurants may differ in terms of capacity planning, menus, store formats (eg drive throughs) and site requirements like parking, ingress/egress and signage.

So, treating all locations in the same way has no upside, while setting strategy for every individual store is an operational nightmare. Distribution planners use store typing to simplify the strategic planning process. This is accomplished by clustering retail units to a workable number of meaningful groups for analysis (see Table 5 for an example).
The clustering process is based on various characteristics including demographics, competition, site-specific variables like accessibility and store format. Store typing can be used for diagnosing operational problems, store performance evaluation and store design/concept planning.

\section{Patronage loyalty and transaction patterns}

The availability of customer and transaction data through a distribution planning system makes analysis of customer patronage and buying patterns much easier than traditional forms of customer survey research. Using loyalty programme data, for example, planners can link transactions across stores to individual customers. These data can then be used to study trip patterns across locations and patronage patterns at locations by time of day and day of week.

Trip 'chain' analysis provides an indication of how and when customers use various locations. These analyses are important for understanding how to serve customers who visit multiple locations. Restaurant and beverage retailers model the time and location of 
Table 4: Market prioritisation

\begin{tabular}{|c|c|c|c|c|c|c|c|c|}
\hline & Pop 2003 & $\begin{array}{l}\text { Deposit } \\
\text { market } \\
\text { (\$ billion) }\end{array}$ & Branches & $\begin{array}{l}\text { Market } \\
\text { share \% }\end{array}$ & $\begin{array}{l}2003 \\
\text { openings }\end{array}$ & $\begin{array}{l}2004 \\
\text { openings }\end{array}$ & $\begin{array}{l}2005 \\
\text { openings }\end{array}$ & $\begin{array}{l}\text { Total } \\
\text { branch } \\
\text { holding } \\
\text { capacity }\end{array}$ \\
\hline Washington DC & 12.2 & 300 & 98 & 18 & 5 & 4 & 3 & 120 \\
\hline Boston, MA & 10.8 & 267 & 48 & 20 & 9 & 10 & 10 & 80 \\
\hline Phoenix, AZ & 3.8 & 90 & 10 & 11 & 2 & 3 & 3 & 20 \\
\hline Las Vegas, NV & 4.2 & 120 & 21 & 34 & 0 & 1 & 1 & 40 \\
\hline
\end{tabular}

visits to determine store placement. For example, coffee retailers serve customers during morning, lunch and evening. Morning visits tend to be in the commute path and locations are most conveniently near the origin (residence) or destination (workplace). Lunch time visits often serve for business meetings and small social groups. Evening visits are often tied to dinner and entertainment trips and are most conveniently located near malls and entertainment centres.

Banks can use trip chain analysis to determine the optimal mix and placement of full-service branches and ATM networks. In this case, for example, a bank may decide that a location that is convenient to its customers but unable to support a branch may be an ideal place to in-fill with an ATM.

Trip pattern analysis is critical for capacity planning and menu planning. By tracking transactions by seasonality, time of day and day of week, retailers can, for example, identify customer experience problems such as long queue times or inventory management.

\section{Impact analysis}

Particularly in merger and acquisitions, retailers and retail banks must assess an acquisition candidate's network strength as part of the due diligence process. Following acquisition, banks must make decisions about which branches should be maintained, upgraded, moved or closed.

The goal of distribution planning in consolidation is to make sure that the right branches are closed and damage to market share is minimised. Consolidation analysis involves identifying redundant coverage in areas of low opportunity among stores that have low patronage loyalty. Closing these branches first will decrease operational and real estate costs without yielding market penetration. Leveraging the locational information in the database, distribution planners review all locations to gather a pool of consolidation candidates. Each candidate is analysed to assess probable impact on the network, to measure sales transfer and capacity impact on receiving locations, and to assess financial implications.

For banks, a key factor is to determine how to reassign accounts to nearby branches in a manner that will minimise account defections. Using spatial analysis, planners can identify the next closest branch that has comparable branch format and service offerings. By taking into account the residential addresses of customers and activity levels across dayparts, planners can determine which branch is most convenient. For example, the new branch will ideally be one located more conveniently than the nearest competitor or in the commuter path between customer residences and employment centres. 
Table 5: Store typing example

\begin{tabular}{|c|c|c|c|c|c|c|c|c|c|}
\hline \multirow[b]{2}{*}{$\begin{array}{l}\text { Upscale } \\
\text { speciality } \\
\text { store }\end{array}$} & \multicolumn{2}{|l|}{ Demand } & \multicolumn{3}{|c|}{ Competition } & & \multicolumn{3}{|c|}{ Quality indices } \\
\hline & $\begin{array}{l}\text { Total } \\
\text { businesses }\end{array}$ & $\begin{array}{l}\text { Total } \\
\text { daytime } \\
\text { population }\end{array}$ & \multicolumn{2}{|c|}{$\begin{array}{l}\text { Direct } \\
\text { affluent } \\
\text { speciality }\end{array}$} & \multicolumn{2}{|c|}{$\begin{array}{l}\text { All } \\
\text { speciality } \\
\text { stores }\end{array}$} & \multicolumn{2}{|c|}{$\begin{array}{l}\text { Total } \\
\text { women's } \\
\text { casual }\end{array}$} & $\begin{array}{l}\text { Total } \\
\text { women's } \\
\text { apparel }\end{array}$ \\
\hline Southfield & 45,321 & $1,297,445$ & 5 & & 149 & & $A$ & & $\mathrm{H}$ \\
\hline Westchester & 33,878 & 172,721 & 1 & & 152 & & $\mathrm{H}$ & & A \\
\hline Watertown & 94,654 & $1,315,999$ & 6 & & 412 & & $\mathrm{H}$ & & $\mathrm{H}$ \\
\hline Crownbrook & 120,923 & $1,626,676$ & 8 & & 257 & & L & & A \\
\hline Ingelston & 96,543 & 233,412 & 3 & & 94 & & $\bar{A}$ & & $\mathrm{~L}$ \\
\hline Capitol & 16,490 & 46,205 & 7 & & 106 & & $\mathrm{~L}$ & & A \\
\hline \multirow[t]{2}{*}{ Northgate } & 19,435 & 49,812 & 4 & & 98 & & $\mathrm{~L}$ & & A \\
\hline & \multicolumn{4}{|c|}{ Demographics } & \multicolumn{4}{|c|}{ Internal data } & \\
\hline $\begin{array}{l}\text { Upscale } \\
\text { speciality } \\
\text { store }\end{array}$ & $\begin{array}{l}2003 \text { total } \\
\text { estimated } \\
\text { population }\end{array}$ & $\begin{array}{l}\text { Populatior } \\
\text { Women in } \\
\text { professior } \\
\text { employme }\end{array}$ & t (\%) & $\begin{array}{l}\text { Income } \\
\text { over } \\
\$ 75,000\end{array}$ & & $\begin{array}{l}\text { Store } \\
\text { square } \\
\text { footage }\end{array}$ & & $\begin{array}{l}\text { Store } \\
\text { location } \\
\text { type }\end{array}$ & $\begin{array}{l}\text { Sales per } \\
\text { square } \\
\text { foot }\end{array}$ \\
\hline Southfield & 785,246 & 24.6 & & 62.5 & & 1,000 & & MALL & $\mathrm{H}$ \\
\hline Westchester & 845,375 & 34.2 & & 74.3 & & 950 & & STRIP & $\mathrm{H}$ \\
\hline Watertown & $3,274,600$ & 8.9 & & 23.1 & & 1,200 & & MALL & $\mathrm{L}$ \\
\hline Crownbrook & $1,500,854$ & 12.3 & & 25.4 & & 1,150 & & MALL & $\mathrm{L}$ \\
\hline Ingelston & $2,538,894$ & 14.5 & & 19.5 & & 900 & & STRIP & A \\
\hline Capitol & $2,699,844$ & 8.4 & & 21.2 & & 950 & & STRIP & $\mathrm{L}$ \\
\hline Northgate & 479,571 & 11.1 & & 28.4 & & 1,000 & & MALL & $\mathrm{L}$ \\
\hline
\end{tabular}

\section{CONCLUSION}

Enterprise-wide distribution planning systems require significant organisational commitment. Unlike customer relationship, enterprise resource planning and other corporate software applications that require the commitment of significant budgets and IT staff, distribution planning systems require greater commitment to data integration and analytical standards. In particular, because of the geographic and customercentric nature of these analyses, most organisations find it necessary to standardise tools, rules about geographic data integration and aggregation, and rules about spatial data analysis at different levels of summarisation. In this manner, functional departments and business units across the enterprise can leverage the same system resources with consistency and accuracy.

\section{Data integration}

New database and analytical applications software provide much greater ease in combining disparate data sources across remote locations. The resulting integrated data sets yield new views into distribution processes and performance. Data integration relies on the use of persistent keys to link customer and transaction data across data sources. Once linked, rules must be developed to aggregate data consistently. For example, customer counts can be summarised by census tract and compared to total household counts in the geography to estimate market penetration.

\section{Analytical standards}

Successful enterprise distribution planning systems promote information sharing across business units and 
functional areas of the organisation. This sharing of information requires agreement on business metrics and data definitions.

At the most elemental level of analysis is the definition of the market and the customer. Independent operating units within a large organisation typically have their own market definitions. This is especially true in companies that have grown through acquisition.

Markets can be defined as aggregations of smaller areas of census or postal geographies. These smaller areas can be rolled up to define larger trade areas, markets and regions. Market metrics including demand potential, market share and penetration rate can then be calculated consistently for any level of aggregation.

When many data must be analysed for markets and regions, such as with location data, however, these aggregations can require significant processing time. To improve calculation efficiencies, some companies will use data from larger standard geographies like metropolitan statistical areas that approximate the same market area.

As retail markets become more competitive, retail leaders look to data-driven strategies for a sustainable advantage. To address the complexities of market analyses, distribution planners are employing enterprise-wide distribution planning systems. These systems rely on a blend of transaction, customer and market-level data. These data can be analysed effectively with a clear understanding of the geospatial assumptions underlying the data and an understanding of which analyses best address each distribution planning decision. 